\title{
Representation Multicultural Values of Text Poetry in the Study Hermeneutics
}

\author{
Muliadi \\ Universitas Muslim Indonesia \\ Makassar, Indonesia
}

\begin{abstract}
Poetry is the result of creative work of the poet. Poet to the poet we can enjoy the beauty of words link full of meaning or value. Values in poetry are very diverse, aesthetic, ethical, religious, and philosophical. Those values are held or raised by the poet in literary works (poems) after a period of contemplation. The period of contemplation is a period to reprocess the process of life, both of which have been passed and imagined. The studied value is multicultural values were the hermeneutics of Ricoeur used as the analysis approach. This is the qualitative research with using source data of Anthology of Husni Djamaluddin Poetries with sub-title "Indonesia, Do You Still My Land?" The procedure of Ricoeur hermeneutic involved three steps. The awareness of space and time had resulted in a reflection. It was that ownership of property did not determine the degree of the magnificence of certain individuals in comparison to other individuals or based on God's will, but measured by their degree of quality in understanding space and time markers.
\end{abstract}

Keywords—poetry, hermeneutics, multicultural

\section{INTRODUCTION}

Poetry representing facts and thoughts, and it helped human learning how to know themselves, another human, other creature, the universe, and God [1]. Based on this understanding, poetry must be made to question or to describe the living by exploiting the mental, mind, and feeling the poet had about the environment [2]. In the journey of life, both human and literature had built a unique world of literature that was characterized by contemplation, religion, imagination, divinity, peace, wisdom, role-model, and others [1].

Literature contained a "value" should be a precious thing because every person had a desire to it. Some values were concrete, but the other was only abstract. Somehow, the abstract value might have a higher position than the concrete [3].

Value has several terms, such as degree, quality, level, the height of thought, religion, community, and others. The value was signified as a thing that was profoundly meaningful, worthy, important, and needed much in human life. Value is something to consider as precious by human or group of humans [4].

Poetry often carried over multicultural value. The word "multicultural" is rooted from multi and culture. The suffix of "ism" was sometimes added, and the end product is multiculturalism. The meaning of multiculturalism is to respect the dignity of a particular human who lived in the community where unique culture [5]. Multiculturalism is an ideology that stressed on recognition and appreciation to the equal standing of different cultures [6].

\section{RESEARCH METHOD}

This research includes qualitative research because the research data is not in the form of numerical data, but the verbal data in the form of a summary, lines, and stanzas in the poem. The source of data for this paper was the Anthology of Husni Djamaluddin [7] Poetries with sub-title "Indonesia, Do You Still My Land?". The format of the data included words, phrases, lines, and paragraphs of the poetries which represented the points of the review.

Hermeneutic was a critical method to interpret the meaning of a text profoundly from a specific language, which also possibly emanated from a particular culture [8]. The procedure of hermeneutic involved several steps. The first step is a symbolical step. The step is understanding symbols one by one. The second step is meaning-embedding by which interpreter used symbols to understand the meaning of the thing or to allow them to explore the meaning in a precise way. The final step is philosophical to think about something using the symbol as the early point of departure. All these steps were closely related to steps of linguistic comprehension, including semantic, reflexive, and existential or ontology [9].

\section{DISCUSSION}

The multicultural philosophical value of the poetry texts reviewed in this paper was about the awareness of space, time, certainty and harmony. The findings of multicultural philosophical value were described as following.

\subsection{Awareness of Space and Time}

Data that manifested multicultural value on the awareness of space and time was a poetry with title "The tap of those ticks" with its verses written following:

\section{The tap of those ticks}

the tick of the clock, the moves of nature

the tap of the ticks of nature, the moves of the time 
the tap of the ticks of the time, the moves of a heart of mine

the tap of the tick of my heart, the moves of you [7]

The multicultural value in Poetry "The tap of those ticks," was known and recognized by observing the information unit of the poetry. For sure, information unit was sentenced unit. To be called a sentence, it must have subject and predicate. Words and phrases in the poetry that were called as the subject would include: the tick of the clock, the tap of the ticks of nature, the tap of the tick of the time, and the tap of the tick of my heart. Meanwhile, the predicate included (is) the moves of nature is the moves of the time, a heart of mine, and the moves of You.

Words and phrases representing the subject were mostly noun or being nounized. As a result, all words or phrases in the subject category would be signified as the material object, and this object could be made understandable through personal sensing device. Therefore, "the tick of the clock" was synonymous with the turn off clock pointer. "The tap of the tick of nature" had a synonym with the shift of daylight and night. "The tap of the tick of the time" was deciphered into a binary set of conditions such as wealthy-poor, lucky-unlucky, healthy-sick, young-old, and others. "The tap of the tick of my heart" was synonymous with the existence of life.

Semantic and reflexive findings led to the recognition that the existence of space and time was not only confined to the sensible material object, but also insensible formal object. The formal object was insensible because it did not nounize things, but was only manifested through linguistic construct and stood as a philosophical statement. Semantic, reflexive, and existential findings had produced an understanding that space and time multiculturalism prevailed for all creatures. Space and time for plants and animals were inscribed as a habitat or a place for a living [3].

\subsection{Certainty}

The following was Poetry "Being."It provided data that represented multicultural value in the aspect of certainty.

\[ \text { Being } \]
being land, submits, being water, flows
being wind, blows, being fire, burns
.................
being me, you decide
$[7]$

The multicultural value in Poetry "Being" was also found and understood by examining its information unit. Information unit was that constituting a sentence. A sentence must have subject and predicate. Words and phrases that stood for the subject in this poetry were (certainty of growing), (certainty of the river), (certainty of the storm), (certainty of heat), (certainty of existence), and (certainty of death). While the predicate included being land (that) submits, being water (that) flows, being wind (that) blows, being fire (that) burns, and being me (that) You decide.
The word "grow" is made synonymous with the rate of an upward move. "River" is synonymous with the elongated concave land. "Storm" is made synonymous with movement. "Heat" is related with flame. "Exist" is equivalent with materialization. "Death" was made equal to a condition of without living pulse. On the other hand, the subject category is also signified with the formal object. "Grow" is a concept of moving into positive side. "River" is a concept about the stream. "Storm" conceptualized a condition of overwhelming. "Heat" is related to a concept of hot through fire. "Exist" is relevant to a concept of something in mind (think). "Death" is a concept referring to something not moved.

Contemplation is needed to muse on the presence of semantic margins of identity. All statements in the subject or predicate categories are formal objects that existed (came to being) in the form of linguistic construct. Semantic and reflexive findings indicated that its complement pair determined the existence of "certainty." The complement pair of certainty for "grow" is "land that submits." In such a way because all creatures needed a place to live, and in this case, this place is "land." If the land is not submissive or is merely rejecting the existence of creatures, then it could be said that all creatures would fail to grow and even be extinct.

The complement pair of the certainty of "river" is "water that streams"; "storm" is "wind that blows"; "heat" must be "fire that burns"; "exist" is "me"; death" is "You (God)." Based on semantic, reflexive, and existential findings above, it is possible that multicultural understanding on particular aspect could be obtained only after acknowledging the complementing pair of the certainty. The complement that caused justice could be acting based on the agreement.

\subsection{Harmony}

Poetry entitled to "in the evening when I want to suicide" was manifesting multicultural value in the aspect of harmony.

\author{
At the evening when I want to suicide \\ those ants, brown ants \\ accurate as players of acrobat \\ collect and lift \\ a grain of fine sugar \\ .............. \\ moreover, without giving up \\ [7]
}

The multicultural value in Poetry "In the evening when I want to suicide" was understandable through information unit. This information unit was sentenced, and in this case, it involved subject and predicate. The poetry had few sentences, and all of them had the same topic, which was those ants. Words and phrases in predicate category included brown ants (first). Accurate as players of Acrobat, collect and lift a grain of fine sugar, approximate and assemble to the wall and the edge of the table, where four others, had waited for them and together carrying over a grain of fine sugar (second). Up,up (third); climbing the white wall with troublesome but tireless and without giving up. 
The word "brown" was the identification of the ant by the color, but it was not only denotative but also connotative. It was asserted in such a way because brown ants also crowded around sugar and had a small size. Bugis-Makassar communities called the little red ants that crowded around sugar with a term "sugar ants." The poet seemed using term "brown ants" to symbolize grass-root community. The semantics of words and sentences above might give a reflection. It was that "achieving collective goals would need harmonic action and hard work. Before the collective goals were truly achieved, it would not proper for one to celebrate the achievement of personal goal when in other side, others still worked hard pursuing their goal and dealing with obstacles hampering the achievement of goals

\section{CONCLUSION}

The awareness of space and time had resulted in a reflection. It was that ownership of property did not determine the degree of the magnificence of certain individuals in comparison to other persons or based on God's will but measured by their level of quality in understanding space and time markers. It is common sense that establishing certainty was requiring persons to be familiar with the environment, object, and subject outside the self, and it was not done by merely examining signs or symptoms inside the mind or presumption. In harmony, it could also be inferred that learning to understand situation beyond the self-was a certainty in the self when the self-was are attempting to establish harmony in the certainty of diversity.

\section{References}

[1] R. Gould, "Philology, Education, Democracy," J. Aesthetic Educ., vol. 46, no. 4, pp. 57-69, 2012.

[2] V. F. Kinloch, "Poetry, literacy, and creativity: Fostering effective learning strategies in an urban classroom," English Educ., vol. 37, no. 2, pp. 96-114, 2005.

[3] D. Heywood and I. Stronach, "Philosophy and hermeneutics," Res. methods Soc. Sci., pp. 114-120, 2005.

[4] J. McCumber, The company of words: Hegel, language, and systematic philosophy. Northwestern University Press, 1993.

[5] J. A. Banks and C. A. M. Banks, Multicultural education: Issues and perspectives. John Wiley \& Sons, 2009.

[6] J. A. Banks, An introduction to multicultural education. ERIC, 1994.

[7] H. Djamaluddin, Indonesia, Masihkah Engkau Tanah Airku?
Jakarta: Pustaka Jaya, 2004.

[8] R. E. Palmer, "Gadamer and Confucius: Some possible affinities," J. Chinese Philos., vol. 33, no. s1, pp. 81-93, 2006.

[9] P. Ricoeur and D. Savage, Freud and philosophy: An essay on interpretation. Motilal Banarsidass Publishers, 2008. 